\title{
MyoD family: a paradigm for development?
}

\section{Eric N. Olson}

Department of Biochemistry and Molecular Biology, The University of Texas M.D. Anderson Cancer Center, Houston, Texas 77030 USA

The establishment of specialized cell types during development involves commitment of multipotential stem cells to specific lineages and subsequent expression of distinct sets of cell type-specific genes. Several gene products that regulate cell fate have been identified in Drosophila and Caenorhabditis elegans, however, the mechanisms that establish complex cellular phenotypes in vertebrates have been more difficult to approach. The recent identification of a family of muscle-specific regulatory factors that can convert fibroblasts to skeletal muscle has contributed significant insight into the events that regulate myogenesis and has provided a framework for understanding the mechanisms that may regulate the establishment of diverse cell types during development.

Early evidence for myogenic regulatory genes came from experiments in which myoblasts were shown to activate muscle genes in a wide variety of nonmyogenic cells when heterokaryons were formed between the two cell types (Blau et al. 1983; Wright 1984). The existence of a "master gene" for the myogenic lineage was also foreseen in studies of the mesodermal stem cell line C3H10T1/2, which can be converted to myoblasts by brief exposure to the demethylating agent 5 -azacytidine (Taylor and Jones 1979). The frequency of conversion of $10 \mathrm{~T}^{1 / 2}$ cells to muscle (up to $50 \%$ ) suggested that one locus or a few closely linked loci were activated following hypomethylation and were responsible for establishing the myogenic lineage (Konieczny and Emerson 1984). This hypothesis was supported by genomic transfection experiments in which DNA from myoblasts, but not from $10 \mathrm{~T}^{1 / 2}$ cells, was shown to convert $10 \mathrm{~T}^{1 / 2}$ cells to myoblasts with a frequency consistent with the involvement of a single regulatory gene (Konieczny et al. 1986; Lassar et al. 1986).

MyoD was the first myogenic regulatory gene to be identified. It was isolated by subtraction-hybridization of cDNAs representing transcripts expressed in myoblasts but not in proliferating 10T $1 / 2$ cells (Davis et al. 1987). MyoD is expressed in myoblasts and skeletal muscle tissue but not in smooth or cardiac muscle or nonmuscle tissue. When the MyoD cDNA is expressed in $10 \mathrm{~T}^{1 / 2}$ cells, it gives rise to stable myogenic clones with the potential to undergo myogenesis. These initial observations supported the appealingly simple conclusion that a single muscle-specific gene was sufficient to generate the complete muscle phenotype, but considerable complexity was soon to follow.

By transfecting $10 \mathrm{~T}^{1 / 2}$ cells with demethylated human
DNA linked to a neomycin-resistance gene, Emerson and co-workers obtained evidence for a genetic locus, myd, that was also sufficient to generate stable myogenic clones (Pinney et al. 1988). Southern analysis showed that myd does not correspond to $M y o D$ or the other known myogenic regulatory genes (see below). The observation that MyoD was expressed constitutively in myd transfectants led to the proposal that these genes may function sequentially in a dependent myogenic regulatory hierarchy. However, given the ability of MyoD and other myogenic regulatory gene products to activate one another's expression, it is equally likely that myd may lie at an equivalent level or even "downstream" of $M y o D$ in a regulatory hierarchy. Until myd is isolated and characterized, its precise mechanism of action and position in the myogenic regulatory hierarchy will remain untestable.

Wright et al. (1989) identified a third myogenic regulatory gene, myogenin, based on the prediction that myoblasts that were able to overcome the inhibitory effect of 5-bromo-2'deoxyuridine (BrdU) on differentiation would overexpress factors involved in activation of the differentiation program. The myogenin cDNA was isolated by subtraction-hybridization of cDNA from BrdU-resistant myoblasts early in the differentiation program against cDNA from myoblasts rendered differentiation defective with BrdU. Subsequently, cDNAs for mouse myogenin (Edmondson and Olson 1989) and the related factors, myf-5 (Braun et al. 1989a) and MRF-4, also called herculin and myf-6 (Rhodes and Konieczny 1989; Braun et al. 1990; Miner and Wold 1990), were isolated independently. All three factors are expressed exclusively in skeletal muscle and have the ability to activate myogenesis in transfected $10 \mathrm{~T}^{1 / 2}$ cells. The predicted amino acid sequences of these factors share $\sim 80 \%$ homology with MyoD within a segment of $\sim 70$ amino acids, which contains a basic domain and a region with homology to the myc family of proteins (Fig. 1). Additional homology among these factors is found in a cysteine/ histidine-rich region immediately amino terminal to the basic domain and a serine/threonine-rich region that resembles a site for phosphorylation near their carboxyl termini.

The conserved basic/myc region of the myogenic factors contains an ancient code for myogenesis and has been found in related muscle-specific factors from mouse (Davis et al. 1987; Edmondson and Olson 1989; Miner and Wold 1990), human (Braun 1989a, 1990), rat (Rhodes and Konieczny 1989; Wright et al. 1989), 


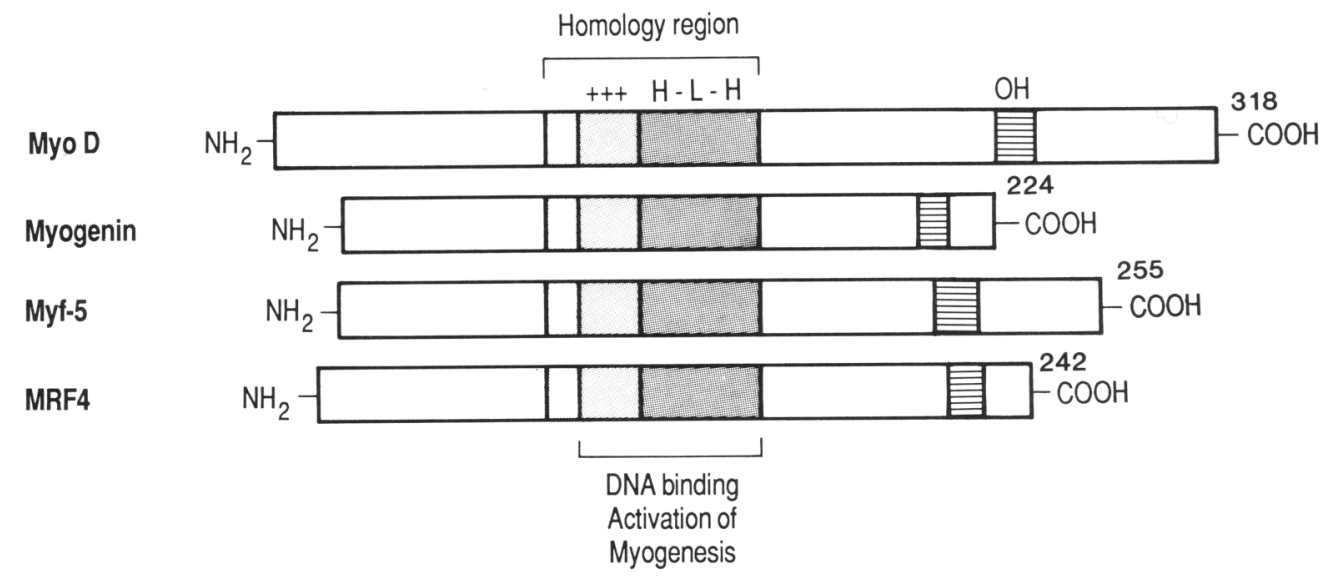

Figure 1. Structural comparison of the myogenic regulatory factors. A linear representation of each myogenic regulatory factor is shown. The region of homology that encompasses the basic $(+++)$ and HLH domains is stippled. The corresponding region of MyoD that is sufficient for myogenesis is indicated at the bottom. The serine/threonine-rich region of homology $(\mathrm{OH})$ is indicated by stripes. The number of amino acids in each polypeptide is shown at the end of each box. The size of myogenin corresponds to that of mouse and human. Only the four mammalian members of the MyoD family are shown. Related factors from other species, such as CMD1 from chicken (Lin et al. 1989), qmf-1 from quail (de la Brousse and Emerson 1990), and XMyoD, XLMF1, and XLMF25 from Xenopus (Hopwood et al. 1989; Scales et al. 1990) are closely related to one or more of these mammalian factors.

Xenopus (Hopwood et al. 1989; Scales et al. 1990), chicken (Lin et al. 1989), quail (de la Brousse and Emerson 1990), Drosophila (A. Michelson, S. Abmayr, and T. Maniatis; B.M. Paterson; both pers. comm.), sea urchin (J. Venuti and W. Klein, pers. comm.), and C. elegans (Benezra et al. 1990). This region of MyoD is necessary and sufficient for conversion of $10 \mathrm{~T}^{1 / 2} / 2$ cells to myoblasts (Tapscott et al. 1988). However, because it also activates expression of the endogenous myogenic regulatory factor genes, it is unclear whether it induces the complete myogenic program directly or indirectly.

If members of the MyoD family are virtually identical in the conserved basic/myc region, and this region is sufficient to activate the complete myogenic program, why are there so many of these factors? It is becoming clear that many nuclear regulatory proteins belong to families that share DNA-binding and dimerization motifs but have diverged in other regions. Such multiplicity provides a mechanism for fine-tuning transcriptional responses while conserving regions of the proteins essential for interaction with a common DNA sequence. Perhaps domains of the myogenic regulatory factors outside the basic/myc region confer subtle specificities on the individual factors that go undetected in the transfection assays used to define their functions. In this regard, ascribing individual functions to these factors has been difficult because of their abilities to activate one another's expression in transfected cells. Gene disruption through homologous recombination will help distinguish the roles of the individual regulatory genes during myogenesis in tissue culture and in vivo.

\section{Myogenic regulatory factors bind muscle-specific control regions}

The myc-similarity domain of the myogenic regulatory factors shares homology with a variety of regulatory gene products, including the Drosophila genes achaete scute (Villares and Cabrera 1987), daughterless (Caudy et al. 1988; Cronmiller et al. 1988), hairy (Rushlow et al. 1989), and Enhancer of split (Klambt et al. 1989), which regulate development of the peripheral nervous system, twist (Thisse et al. 1988), which participates in the establishment of the germ layers, and the widely expressed immunoglobulin enhancer-binding factors E12, E47 (Murre et al. 1989a), E2-2, and E2-5 (Henthorn et al. 1990). This region of homology has been postulated to adopt a helix-loop-helix $(\mathrm{HLH})$ conformation in which two amphipathic $\alpha$-helices are separated by an intervening loop of variable length. Dimerization, a prerequisite for binding of HLH-containing proteins to DNA, is mediated by the HLH domain (Murre et al. 1989a,b; Davis et al. 1990). Such ubiquitously expressed HLH proteins as E12, E47, and the daughterless gene product preferentially form heterodimers with cell type-specific HLH proteins, such as MyoD, myogenin, and the achaete scute complex $(A S-C)$ gene products. HLH homo- and heterodimers bind to a consensus sequence referred to as an E box (CANNTG), which was first identified within the immunoglobulin enhancers (Church et al. 1985) and has subsequently been found in regulatory regions of most, but not all, muscle-specific genes (Buskin and Hauschka 1989), as well as in other cell type-specific enhancers (Moss et al. 1988). In addition to the enormous potential for regulatory diversity imparted by heterodimerization among different combinations of $\mathrm{HLH}$ proteins, the ability of different HLH heterodimers to recognize a common DNA sequence provides opportunities for regulation through competition for DNA binding. The exact nature of the oligomeric complexes in which the myogenic factors participate in vivo remains to be defined, but in light of the relatively low 
efficiency of homodimerization and the presence of numerous E12-like proteins in muscle cells, it is doubtful that homodimers of the myogenic factors are the principle biologically active species.

Members of the MyoD family have been shown to trans-activate reporter genes linked to muscle-specific control regions in a variety of nonmyogenic cell types in which these genes are normally inactive (Braun et al. 1989a, 1990; Edmondson and Olson 1989; Lin et al. 1989; Davis et al. 1990; Yutzey et al. 1990). The control region for the muscle creatine kinase (MCK) gene has been examined in detail and contains two $\mathrm{E}$ boxes that bind homodimers of the myogenic factors with low affinity and heterodimers formed between E12 and the myogenic regulatory factors with high affinity in vitro (Buskin and Hauschka 1989; Lassar et al. 1989b; Murre et al. 1989b; Braun et al. 1990; Brennan and Olson 1990). The $\mathrm{E}$ boxes in the MCK enhancer are necessary but not sufficient for full enhancer activity, indicating that transcriptional activation involves interactions between the myogenic regulatory factors and other factors that bind nearby sites (Gossett et al. 1989). If cooperative interactions with other transcription factors were mediated by domains outside of the basic/myc region, each individual myogenic factor could interact with different subsets of transcription factors and thereby selectively activate different target genes, depending on the elements adjacent to the $\mathrm{E}$ boxes in each muscle control region.

Although most muscle-specific regulatory regions contain potential binding sites for the myogenic factors, a subset of muscle-specific genes such as $\alpha$-skeletal actin (Bergsma et al. 1986) and myosin heavy chain (Bouvagnet et al. 1987) does not contain E boxes within their cis-regulatory regions. How, then, are these genes controlled? Conceivably, the myogenic factors could bind sequences other than the CANNTG consensus, perhaps as components of complexes with proteins not yet identified. Alternatively, or in addition, these factors may control some muscle genes indirectly. In this regard, three nuclear factors from muscle cells, MAPF2 (Walsh and Schimmel 1987), MEF-2 (Gossett et al. 1989), and MCAT-binding factor (Mar and Ordahl 1990), have been identified and shown to bind sequences distinct from $\mathrm{E}$ boxes within muscle-specific control regions. The relationship of these factors to the $\mathrm{HLH}$-containing myogenic factors, as well as the exact positions of these factors in the myogenic regulatory hierarchy, remains to be defined.

Mutagenesis of MyoD indicates that the basic domain and HLH are sufficient for binding to the MCK enhancer and that these domains are functionally distinct (Davis et al. 1990). The HLH is important in specifying partners for heterodimerization and does not seem to contain information required specifically for myogenesis, as the corresponding region of the Drosophila T4 AS-C gene product can substitute for this region and activate myogenesis (Davis et al. 1990). The basic domain of MyoD is essential for sequence-specific DNA binding and activation of myogenesis (Davis et al. 1990). Interestingly, substitution of the basic domain of MyoD with the corresponding domains of E12 or Drosophila T4 AS-C results in chimeric proteins that heterodimerize with E12 and bind the MCK enhancer, but they do not activate the enhancer or convert $10 \mathrm{~T}^{1 / 2} 2$ cells to myoblasts. These results indicate that the specificity for myogenesis is encoded by the basic region of MyoD and that this "activation function" depends on, but can be distinguished from, DNA binding.

How can the basic domain of MyoD activate transcription from muscle control regions while the corresponding domains of other HLH proteins cannot? This domain could serve as a site for interaction with an accessory protein essential for muscle-specific transcription. Alternatively, the basic domain could undergo a post-translational modification essential for transcriptional activation, or its interaction with the DNA could induce a conformational change in the protein leading to activation.

\section{Members of the MyoD family are regulated differently}

The pattern of expression of the myogenic regulatory factors during embryogenesis suggests they may be used at different developmental stages and perhaps play dual roles in determination and differentiation within the myogenic lineage. Establishment of muscle during vertebrate embryogenesis involves induction of primary ectoderm to mesoderm, a portion of which segregates to the somites. Subsequently, myogenic precursor cells migrate into the developing limb bud. Myogenin transcripts are detected at high levels in the somite myotome 2 days before the appearance of $\mathrm{MyoD}$ or other muscle-specific genes, suggesting that the initial specification of muscle may be independent of MyoD (Sassoon et al. 1989; Wright et al. 1989). A quail myogenic factor, qmf-1, which may be a composite between MyoD and myf-5, is also expressed in the embryonic myotome and appears initially in the dorsal medial lip of the somite dermatome; this may be the initial site for myogenic lineage determination (de la Brousse and Emerson 1990). Paradoxically, cells that invade the limb bud and ultimately differentiate into muscle initially show no expression of myogenin or MyoD but later express both coordinately. Several lines of evidence indicate that the fate of these cells - to become muscle-is already determined, suggesting they were derived from cells in the somite that do not express myogenin or MyoD or, more likely, that cells from the somite myotome repress the expression of these factors as they migrate into the limb bud. In contrast to the early expression of myogenin and MyoD, MRF-4 is not expressed until after birth, when it increases to the highest level of the myogenic factors (Rhodes and Konieczny 1989; see also Braun et al. 1990; Miner and Wold 1990).

MyoD mRNA is present at low levels in Xenopus oocytes and is rapidly up-regulated in early gastrulae in regions of prospective mesoderm, where it is the earliest marker for mesoderm induction so far identified (Hopwood et al. 1989; Scales et al. 1990). In later stage 
Xenopus embryos, MyoD expression is restricted to the developing somites and declines after somitogenesis. Given the apparent roles of peptide growth factors and the homeotic genes Mix.1 and Xhox.3 in generating muscle in Xenopus embryos (Ruiz i Altaba and Melton 1989|, this should be an important system for elucidating the regulatory cues that impinge on the myogenic regulatory genes early in embryogenesis.

An intriguing property of the myogenic regulatory factors is their ability to autoregulate their own and activate one another's expression. Such regulatory interactions may serve to reinforce the decision to differentiate and confer stability to the myogenic phenotype. For reasons that are unclear, $10 \mathrm{~T}^{1 / 2}$ cells are especially permissive for cross-activation of the myogenic factors, whereas most other cell types do not support these regulatory interactions (Braun et al. 1989b; Thayer et al. 1989). Within most established muscle cell lines, only subsets of the myogenic regulatory factors are expressed, suggesting that other cellular factors can influence regulatory interactions among members of the $\mathrm{MyoD}$ family. For example, either MyoD or myf-5, but not both, is expressed constitutively in many muscle cell lines (Davis et al. 1987; Braun et al. 1989a,b). In contrast, myogenin is repressed until myoblasts are triggered to differentiate and is then rapidly up-regulated in every muscle cell line that has been examined (Edmondson and Olson 1989; Wright et al. 1989). MRF-4 is not expressed in most established muscle cell lines, which is consistent with its possible role in later development (Rhodes and Konieczny 1989; see also Braun et al. 1990; Miner and Wold 1990). The mechanism that accounts for selective expression of certain members of the MyoD family in some cell types is unknown.

Could different combinations of the four known myogenic regulatory factors contribute to the unique properties of different muscle cell types or provide the basis for myofiber diversity? The phenotype of the $\mathrm{BC}_{3} \mathrm{H} 1$ muscle cell line supports this notion. These cells express myogenin and most other muscle-specific genes, but they do not express MyoD nor do they commit to terminal differentiation or form multinucleate myotubes (Edmondson and Olson 1989). Expression of an exogenous MyoD cDNA in $\mathrm{BC}_{3} \mathrm{Hl}$ cells can rescue their ability to form terminally differentiated myotubes, suggesting that the actions of myogenin and MyoD are not entirely redundant and that $\mathrm{MyoD}$ may be required for certain aspects of the differentiation program (Brennan et al. 1990).

\section{Antagonism between growth factors and the MyoD family}

In myoblasts, the decision to differentiate appears to be determined by a balance between positive signals, elicited by members of the MyoD family, and negative signals, generated by exogenous growth factors. High concentrations of serum or certain peptide growth factors, for example, can block expression of muscle-specific genes in cells that express myogenic factors consti- tutively (Davis et al. 1987; Edmondson and Olson 1989; Vaidya et al. 1989). Conversely, high levels of MyoD expression can suppress cell growth and lead to differentiation, even in the presence of high concentrations of mitogens or activated oncogenes (Konieczny et al. 1989; Lassar 1989a).

How might members of the MyoD family suppress proliferation? Inhibition of cell growth could be a consequence of differentiation or it could be an independent phenomenon. Perhaps members of the MyoD family interact directly with the control regions of genes required for proliferation or interfere with the actions of growth factor-inducible early gene products, such as fos, myc, or iun. Expression of the myogenic regulatory factors at high levels also could suppress growth by "squelching" (Ptashne 1988) or "transcriptional interference" (Meyer et al. 1989), as a consequence of their interaction with cellular factors required for proliferation.

The mechanism through which growth factors override the actions of the myogenic regulatory factors is also an enigma. MyoD and myogenin are known to be phosphorylated, which raises the possibility that changes in their phosphorylation might account for the inhibitory effects of growth factors on their actions. At present, however, the domains of these proteins that are phosphorylated and the kinases for which they are substrates have yet to be defined. Growth factors also could block the actions of the myogenic factors through induction of inhibitory cellular factors.

One candidate for a mediator of the negative effects of growth factors on myogenesis is a novel HLH protein called Id (inhibitor of DNA binding), which is expressed in a wide range of cell types and is down-regulated during differentiation of myoblasts (Benezra et al. 1990). Id can heterodimerize with E12 and, to a lesser extent, with MyoD, but it lacks a basic domain, which has been postulated to lead to negative regulation through the formation of nonfunctional heterodimers that cannot bind DNA. Down-regulation of Id during myogenesis has been proposed to release E12 for heterodimerization with $\mathrm{MyoD}$, thereby leading to activation of the differentiation program. Inhibition of the DNA-binding activity of MyoD in myoblasts is consistent with in vivo footprinting experiments, showing that the high-affinity $E$ box in the MCK enhancer becomes occupied only after myoblasts have been triggered to differentiate by withdrawal of serum, despite high levels of MyoD expression prior to differentiation (Mueller and Wold 1989).

The actions of the MyoD family are governed by other cellular factors

The dependence of the myogenic regulatory factors on dimerization for activation of myogenesis suggests that their actions can be dictated by the repertoire of cellular factors with which they can interact. This prediction is supported by studies of the susceptibility of different cell types to myogenic conversion. Although $10 \mathrm{~T}^{1 / 2}$ cells and fibroblasts of mesodermal origin are clearly the most susceptible to the actions of MyoD, forced expres- 
sion of MyoD will also activate some aspects of myogenesis in determined cell types from all three germ layers, including fibroblast, melanoma, neuroblastoma, adipocyte, and, perhaps, some types of liver cells (Lin et al. 1989; Weintraub et al. 1989). In many of these cell types, however, only certain aspects of the differentiation program are activated transiently. There are also certain cells of nonmesodermal origin such as HeLa, HepG2 (liver), and CV-1 (kidney), which appear refractory to myogenic conversion by MyoD (Weintraub et al. 1989; Schafer et al. 1990). The failure of MyoD to activate myogenesis in these cells suggests that the factors with which it cooperates are not ubiquitous or that there are negative factors present in some cell types. Indeed, heterokaryon experiments have provided evidence for positive and negative factors, which might or might not be HLH proteins, that can determine cellular responsiveness to MyoD and myogenin (Schafer et al. 1990).

It is intriguing that in some cell types, such as melanoma, neuroblastoma (Weintraub et al. 1989), and osteosarcoma (Chen and Jones 1990), the endogenous differentiation program and the myogenic program under control of MyoD appear to be compatible, whereas in other cell types, such as adipocytes, the endogenous developmental program is extinguished by forced expression of MyoD (Weintraub et al. 1989). Could the ability of MyoD to extinguish certain differentiation programs reflect competition between $\mathrm{MyoD}$ and other cell typespecific HLH proteins for interaction with E12? This question could potentially be answered by using mutants in the basic domain of MyoD or its relatives, which retain the ability to heterodimerize. Such mutants would be predicted to extinguish endogenous developmental programs without activating myogenesis if the inhibitory effects of $\mathrm{MyoD}$ reflect competition for interaction with endogenous HLH proteins.

\section{Can the MyoD family account for all aspects of myogenesis?}

$10 \mathrm{~T}^{1 / 2}$ cells have provided an adventitious system for identifying and characterizing the HLH family of myogenic regulatory factors. However, there seems little doubt that other tissue-specific factors act upstream, downstream, and, perhaps, in parallel with members of the MyoD family. The recent demonstration that avian retroviruses expressing v-ski can activate myogenesis in quail embryo fibroblasts supports this notion /Colmenares and Stavnezer 1989|. The behavior of myoblasts exposed to BrdU also suggests the existence of regulatory factors that act upstream of the MyoD family. Incorporation of BrdU into myoblast DNA extinguishes the expression of MyoD (Tapscott et al. 1989), whereas when BrdU-inhibited myoblasts are placed in medium lacking BrdU, they rapidly recover the ability to differentiate (Wright 1982) and re-express MyoD. Thus, there must be a memory of the determined state that would appear to be independent of the MyoD family. Similarly, expression of activated ras and fos extinguishes the expression of MyoD and myogenin, yet myoblasts trans- formed with these oncogenes continue to express a subset of muscle-specific genes (Konieczny et al. 1989; Lassar et al. 1989a; Shih et al. 1990) and can reactivate the complete differentiation program upon removal of the oncogenic signal (Holtzer et al. 1975; Gossett et al. 1988). Myoblast cell lines that are determined, but do not express $\mathrm{MyoD}$ or myogenin until they have initiated differentiation, also suggest that additional factors are responsible for maintaining myoblasts in the lineage (Montarras et al. 1989).

\section{Is the MyoD family a model for the regulation of diverse cellular phenotypes?}

Do genes analogous to those of the MyoD family regulate cell fate in other lineages? Obvious cell types to consider are smooth and cardiac muscle, which express several muscle-specific genes that are regulated by the MyoD family in skeletal muscle. It is tempting to speculate that similarities between these different muscle cell types reflect a common underlying regulatory scheme, but genes sharing homology with the MyoD family have not yet been detected in smooth or cardiac muscle by low stringency hybridization to the known members of the MyoD family; this suggests that if such regulatory genes exist, they have diverged considerably from those that regulate the skeletal muscle lineage.

Several observations suggest the involvement of HLH proteins in cell types other than muscle. In addition to the positive roles played by products of the $A S-C$ and the daughterless gene product in Drosophila neurogenesis, there is recent evidence for negative HLH proteins analogous to Id that antagonize their actions (Ellis et al. 1990; Garrell and Modolell 1990; see also Benezra et al. 1990). The presence of $E$ boxes in numerous cell typespecific enhancers (Church et al. 1985; Moss et al. 1988; Murre et al. 1989a) also suggests that the associated genes will be regulated by HLH proteins. Finally, the ubiquitous expression of E12 and E47 suggests that cell type-specific partners for heterodimerization, analogous to the myogenic regulatory factors, may participate in enhancer regulatory systems that modulate gene expression in a wide range of cell types.

\section{Future prospects}

Despite significant inroads into the identities of factors that can activate the muscle differentiation program in tissue culture, numerous unanswered questions remain. What are the functional differences between the known members of the MyoD family? What are the identities and mechanisms of action of the different factors that cooperate with, and antagonize the actions of, the myogenic regulatory factors? Are the proteins with which the MyoD family members interact in cell culture the same as those in vivo, or do they represent just a small subset? What are the normal developmental cues that trigger commitment to the myogenic lineage during embryogenesis, and what roles do the known myogenic regulatory factors play within the developing somite? Do 
the myogenic regulatory factors play dual roles in determination and differentiation and, if so, how do they discriminate between the genes that must be activated in each developmental state? What is the molecular basis for the antagonism between the actions of growth factors and members of the MyoD family? Do the mechanisms that control myogenesis operate in other cell types?

Clearly, members of the MyoD family do not function alone but participate in a regulatory network that involves dynamic interplay among a variety of positive and negative factors. The components of the regulatory circuitry of myogenesis have begun to be defined only within the limited context of a subset of tissue culture cells. Further investigation into the relevance of these observations to normal embryogenesis will undoubtedly not only shed light on the molecular basis of the myogenic phenotype but also on the fundamental mechanisms responsible for the specification of cell fate in diverse lineages during development.

\section{Acknowledgements}

The comments of Mike Perry, Bill Klein, and members of this laboratory are greatly appreciated.

The publication costs of this article were defrayed in part by payment of page charges. This article must therefore be hereby marked "advertisement" in accordance with 18 USC section 1734 solely to indicate this fact.

\section{References}

Benezra, R., R.L. Davis, D. Lockshon, D.L. Turner, and H. Weintraub. 1990. The protein Id: A negative regulator of helix-loop-helix DNA binding proteins. Cell 61: 49-59.

Bergsma, D.J., J.M. Grichnik, L.M.A. Gossett, and R.J. Schwartz. 1986. Delimitation and characterization of cisacting DNA sequences required for the regulated expression and transcriptional control of the chicken skeletal $\alpha$-actin gene. Mol. Cell. Biol. 6: 2462-2475.

Blau, H.M., C.P. Chiu, and C. Webster. 1983. Cytoplasmic activation of human nuclear genes in stable heterocaryons. Cell 32: $1171-1180$.

Bouvagnet, P.F., E.E. Strehler, G. E. White, M.-A. Strehler-Page, B. Nadal-Ginard, and V. Mahdavi. 1987. Multiple positive and negative $5^{\prime}$ regulatory elements control the cell-typespecific expression of the embryonic skeletal myosin heavychain gene. Mol. Cell. Biol. 7: 4377-4389.

Braun, T., G. Buschhausen-Denker, E. Bober, E. Tannich, and H.H. Arnold. 1989a. A novel human muscle factor related to but distinct from MyoDl induces myogenic conversion in $10 \mathrm{~T}^{1} / 2$ fibroblasts. $E M B O$ I. 8: 701-709.

Braun, T., E. Bober, G. Buschhausen-Denker, S. Kotz, K. Grzeschik, and H.H. Arnold. 1989b. Differential expression of myogenic determination genes in muscle cells: Possible autoactivation by the Myf gene products. $E M B O$ I. 8: $3617-$ 3625.

Braun, T., E. Bober, B. Winter, N. Rosenthal, and H.H. Arnold. 1990. Myf-6, a new member of the human gene family of myogenic determination factors: Evidence for a gene cluster on chromosome 12. EMBO I. 9: 821-831.

Brennan, T.J. and E.N. Olson. 1990. Myogenin resides in the nucleus and acquires high affinity for a conserved enhancer element on heterodimerization. Genes Dev. 4: 582-595.

Brennan, T.J., D.G. Edmondson, and E.N. Olson. 1990. Aberrant regulation of $\mathrm{MyoDl}$ contributes to the partially defective myogenic phenotype of $\mathrm{BC}_{3} \mathrm{Hl}$ cells. I. Cell Biol. 110: $929-937$.

Buskin, J.N. and S.D. Hauschka. 1989. Identification of a myocyte-specific nuclear factor which binds to the muscle-specific enhancer of the mouse muscle creatine kinase gene. Mol. Cell. Biol. 9: 2627-2640.

Caudy, M., H. Vassin, M. Branc, R. Tuma, L. Yeh Jan, and Y.N. Jan. 1988. daughterless a Drosophila gene essential for both neurogenesis and sex determination, has sequence similarities to myc and the achaete-scute complex. Cell 55: 10611067.

Chen, J. and P. Jones. 1990. Potentiation of MyoDl activity by 5-aza-2'deoxycytidine. Cell Growth Differ. 1 (in press).

Church, G.M., A. Ephrussi, W. Gilbert, and S. Tonegawa. 1985. Cell type specific contacts to immunoglobulin enhancers in nuclei. Nature 313: 798-801.

Colmenares, C. and E. Stavnezer. 1989. The ski oncogene induces muscle differentiation in quail embryo cells. Cell 59: 293-303.

Cronmiller, C., P. Schedl, and T. Cline. 1988. Molecular characterization of daughterless, a Drosophila sex determination gene with multiple roles in development. Genes Dev. 2: $1666-1676$.

Davis, R.L., H. Weintraub, and A.B. Lassar. 1987. Expression of a single transfected cDNA converts fibroblasts to myoblasts. Cell 51: $987-1000$.

Davis, R.L., P.-F. Cheng, A.B. Lassar, and H. Weintraub. 1990. The MyoD DNA binding domain contains a recognition code for muscle-specific gene activation. Cell 60: 733-746.

de la Brousse, C.F. and C.P. Emerson, Jr. 1990. Localized expression of a myogenic regulatory gene, $q m f 1$, in the somite dermatome of avian embryos. Genes Dev. 4: 567-581.

Edmondson, D.G. and E.N. Olson. 1989. A gene with homology to the myc similarity region of $\mathrm{MyoDl}$ is expressed during myogenesis and is sufficient to activate the muscle differentiation program. Genes Dev. 3: 628-640.

Ellis, H.M., Spann, D.R., and J.W. Posakony. 1990. extramacrochaetae, a negative regulator of sensory organ development in Drosophila, defines a new class of helix-loop-helix proteins. Cell 61: 27-38.

Garrell, J. and J. Modolell. 1990. The Drosophila extramacrochaetae locus, an antagonist of proneural genes that, like these genes, encodes a helix-loop-helix protein. Cell 61: 3948.

Gossett, L.A., W. Zhang, and E.N. Olson. 1988. Dexamethasone-dependent inhibition of differentiation of $\mathrm{C} 2$ myoblasts bearing steroid-inducible N-ras oncogenes. I. Cell Biol. 106: 2127-2137.

Gossett, L., D. Kelvin, E. Sternberg, and E.N. Olson. 1989. A new myocyte-specific enhancer binding factor that recognizes a conserved element associated with multiple musclespecific genes. Mol. Cell. Biol. 9: 5022-5033.

Henthorn, P., M. Kiledjian, and T. Kadesch. 1990. Two distinct transcription factors that bind the immunoglobulin enhancer uE5/kE2 motif. Science 247: 467-470.

Holtzer, H., J. Biehl, G. Yeoh, R. Meganathan, and A. Kaji. 1975. Effect of oncogenic virus on muscle differentiation. Proc. Natl. Acad. Sci. 72: 4051-4055.

Hopwood, N.D., A. Pluck, and J.B. Gurdon. 1989. MyoD expression in the forming somites is an early response to mesoderm induction in Xenopus embryos. EMBO f. 8: 34093417.

Klambt, C., E. Knust, K. Tietze, and J.A. Campos-Ortega. 1989. 
Closely related transcripts encoded by the neurogenic gene complex Enhancer of split of Drosophila melanogaster. EMBO I. 8: 203-210.

Konieczny, S. F. and C. P. Emerson Jr. 1984. 5-azacytidine induction of stable mesodermal stem cell lineages from $10 \mathrm{~T}^{1 / 2}$ cells: evidence for regulatory genes controlling determination. Cell 38: 791-800.

Konieczny, S.F., A.S. Baldwin, and C.P. Emerson, Jr. 1986. Myogenic determination and differentiation of $10 \mathrm{~T}^{1 / 2}$ cell lineages: Evidence for a simple genetic regulatory system. In Molecular and cellular biology, new series/ed. C.P. Emerson, D. Fischman, B. Nadal-Ginard, and M.A.Q. Siddiqui), vol. 29 C, pp. 21-34. Alan R. Liss, New York.

Konieczny, S.F., B.L. Drobes, S.L. Menke, and E.J. Taparowsky. 1989. Inhibition of myogenic differentiation by the H-ras oncogene is associated with the down regulation of the MyoD1 gene. Oncogene 4: 473-481.

Lassar, A.B., B.M. Paterson, and H. Weintraub. 1986. Transfection of a DNA locus that mediates the conversion of $10 \mathrm{~T}^{1 / 2}$ fibroblasts to myoblasts. Cell 47: 649-656.

Lassar, A.B., M.J. Thayer, R.W. Overell, and H. Weintraub. 1989a. Transformation by activated RAS or FOS prevents myogenesis by inhibiting expression of MyoD1. Cell 5: $659-667$.

Lassar, A.B., J.N. Buskin, D. Lockshon, R.L. Davis, S. Apone, S.D. Hauschka, and H. Weintraub. 1989b. MyoD is a sequence-specific DNA binding protein requiring a region of myc homology to bind to the muscle creatine kinase enhancer. Cell 58: 823-831.

Lin, A.-Y., C.A. Dechesne, J. Eldridge, and B.M. Paterson. 1989. An avian muscle factor related to $\mathrm{MyoDl}$ activates musclespecific promoters in nonmuscle cells of different germlayer origin and in BrdU-treated myoblasts. Genes Dev. 3: 986-996.

Mar, J.H. and C.P. Ordahl. 1990. M-CAT binding factor, a novel trans-acting factor governing muscle-specific transcription. Mol. Cell. Biol. 10: 4271-4283.

Meyer, M.-E., B. Gronemeyer, M.-T. Turcotte, D. Bocqel, D. Tasset, and P. Chambon. 1989. Steroid hormone receptors compete for factors that mediate their enhancer functions. Cell 57: 433-442.

Miner, J.H. and B. Wold. 1990. Herculin, a fourth member of the MyoD family of myogenic regulatory genes. Proc. Natl. Acad. Sci. 87: 1089-1093.

Montarras, D., C. Pinset, J. Chelly, A. Kahn, and F. Gros. 1989. Expression of MyoD1 coincides with terminal differentiation in determined but inducible muscle cells. $E M B O \mathrm{f}$. 8: $2203-2207$.

Moss, L.G., J.B. Moss, and W.J. Rutter. 1988. Systematic binding analysis of the insulin gene transcription control region: Insulin and immunoglobulin enhancers utilize similar transactivators. Mol. Cell. Biol. 8: 2620-2627.

Mueller, P.R. and B. Wold. 1989. In vivo footprinting of a muscle specific enhancer by ligation mediated PCR. Science 246: $780-786$.

Murre, C., P.S. McCaw, and D. Baltimore. 1989a. A new DNA binding and dimerization motif in immunoglobulin enhancer binding, daughterless, MyoD, and myc proteins. Cell 56: $777-783$.

Murre, C., P.S. McCaw, H. Vaessin, M. Caudy, L.Y. Jan, Y.N. Jan, C.V. Cabrera, J.N. Buskin, S.D. Hauschka, A.B. Lassar, H. Weintraub, and D. Baltimore. 1989b. Interactions between heterologous helix-loop-helix proteins generate complexes that bind specifically to a common DNA sequence. Cell 58: 537-544.

Pinney, D.F., S.H. Pearson-White, S.F. Konieczny, K.E. Latham, and C.P. Emerson, Jr. 1988. Myogenic lineage determination and differentiation: Evidence for a regulatory gene pathway. Cell 53: 781-793.

Ptashne, M. 1988. How eucaryotic transcriptional activators work. Nature 335: 683-689.

Rhodes, S.J. and S.F. Konieczny. 1989. Identification of MRF4: A new member of the muscle regulatory factor gene family. Genes Dev. 3: 2050-2061.

Ruiz i Altaba, A. and D. Melton. 1989. Interaction between peptide growth factors and homeobox genes in the establishment of antero-posterior polarity in frog embryos. $\mathrm{Na}$ ture 341: 33-38.

Rushlow, C.A., A. Hogan, S.M. Pinchin, K.M. Howe, M. Lardelli, and D. Ish-Horowicz. 1989. The Drosophila hairy protein acts in both segmentation and bristle patterning and shows homology to N-myc. EMBO I. 8: 3095-3103.

Sassoon, D., G. Lyons, W.E. Wright, V. Lin, A. Lassar, H. Weintraub, and M. Buckingham. 1989. Expression of two myogenic regulatory factors myogenin and $M y o D 1$ during mouse embryogenesis. Nature 341: 303-307.

Scales, J., E.N. Olson, and W.M. Perry. 1990. Two distinct Xenopus genes with homology to MyoDl are expressed before somite formation in early embryogenesis. Mol. Cell. Biol. 10: 1516-1524.

Schafer, B.W., B.T. Blakely, G.J. Darlington, and H.M. Blau. 1990. Effect of cell history on response to helix-loop-helix family of myogenic regulators. Nature 344: 454-458.

Shih, H.-T., M.S. Wathen, H.B. Marshall, J.M. Caffrey, and M.D. Schneider. 1990. Dihydropyridine receptor gene expression is regulated by inhibitors of myogenesis and is relatively insensitive to denervation. J. Clin. Invest. 85: 781789.

Tapscott, S.J., A.B. Lassar, R.L. Davis, and H. Weintraub. 1989. 5-Bromo-2'-deoxyuridine blocks myogenesis by extinguishing expression of MyoDl. Science 245: 532-536.

Tapscott, S.J., R.L. Davis, M.J. Thayer, P.-F. Cheng, H. Weintraub, and A.B. Lassar. 1988. MyoDl: A nuclear phosphoprotein requiring a myc homology region to convert fibroblasts to myoblasts. Science 242: 405-411.

Taylor, S.M. and P.A. Jones. 1979. Multiple new phenotypes induced in $10 \mathrm{~T}^{1} / 2$ and $3 \mathrm{~T} 3$ cells treated with 5-azacytidine. Cell 17: 771-779.

Thayer, M.J., S.J. Tapscott, R.L. Davis, W.E. Wright, A.B. Lassar, and H. Weintraub. 1989. Positive autoregulation of the myogenic determination gene MyoDl. Cell 58: 241248.

Thisse, B., C. Stoetzel, C. Gorostiza-Thisse, and F. PerrinSchmitt. 1988. Sequence of the twist gene and nuclear localization of its protein in endomesodermal cells of early Drosophila embryos. EMBO I. 7: 2175-2183.

Vaidya, T.B., S.J. Rhodes, E.J. Taparowsky, and S.F. Konieczny. 1989. Fibroblast growth factor and transforming growth factor $\beta$ repress transcription of the myogenic regulatory gene MyoDl. Mol. Cell. Biol. 9: 3576-3579.

Villares, R. and C.V. Cabrera. 1987. The acheate-scute gene complex of D. melanogaster: conserved domains in a subset of genes required for neurogenesis and their homology to myc. Cell 50: 415-424.

Walsh, K. and P. Schimmel. 1987. Two nuclear factors compete for the skeletal muscle actin promoter. I. Biol. Chem. 262: 9429-9432.

Weintraub, H., S.J. Tapscott, R.L. Davis, M.J. Thayer, M.A. Adam, A.B. Lassar, and A.D. Miller. 1989. Activation of muscle specific genes in pigment, nerve, fat, liver and fibroblast cell lines by forced expression of MyoD. Proc. Natl. Acad. Sci. 86: 5434-5438. 
Wright, W.E. 1982. The BrdU content of DNA is decreased during reversal of inhibition of myogenesis by deoxycytidine. Som. Cell Genet. 8: 547-555.

. 1984. Expression of differentiated functions in heterokaryons between skeletal myocytes, adrenal cells, fibroblasts and glial cells. Exp. Cell. Res. 151: 55-69.

Wright, W.E., D.A. Sassoon, and V.K. Lin. 1989. Myogenin, a factor regulating myogenesis, has a domain homologous to MyoD1. Cell 56: 607-617.

Yutzey, K.E., S.J. Rhodes, and S.F. Konieczny. 1990. Differential trans-activation associated with the muscle regulatory factors MyoDl, myogenin and MRF4. Mol. Cell. Biol. 10: $3934-3944$. 


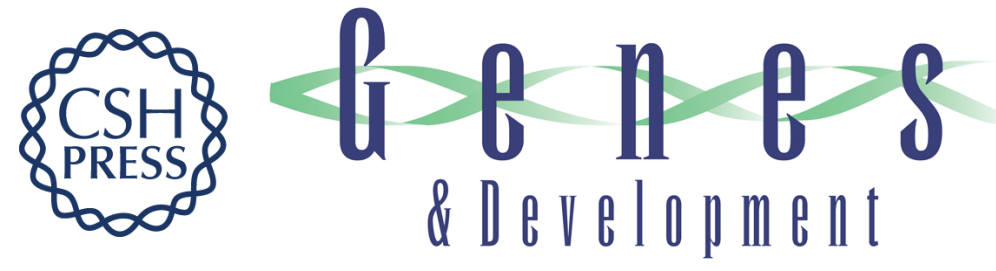

\section{MyoD family: a paradigm for development?}

E N Olson

Genes Dev. 1990, 4:

Access the most recent version at doi:10.1101/gad.4.9.1454

References This article cites 62 articles, 25 of which can be accessed free at: http://genesdev.cshlp.org/content/4/9/1454.full.html\#ref-list-1

License

Email Alerting

Receive free email alerts when new articles cite this article - sign up in the box at the top Service right corner of the article or click here.

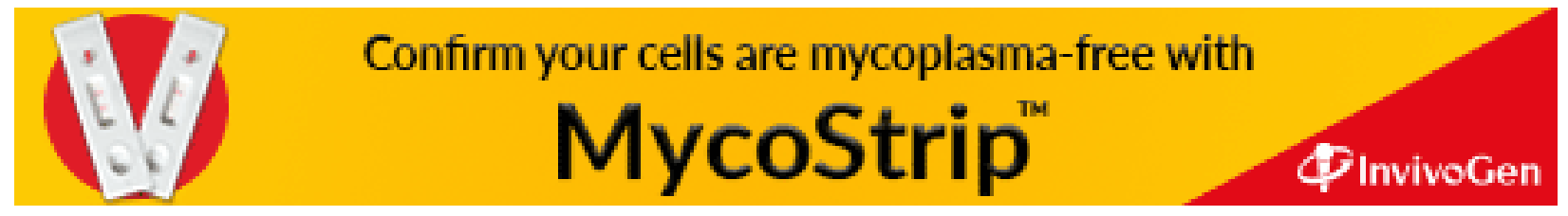

